\title{
Contributions of Calcium-Dependent and Calcium-Independent Mechanisms to Presynaptic Inhibition at a Cerebellar Synapse
}

\author{
Jeremy S. Dittman and Wade G. Regehr \\ Department of Neurobiology, Harvard Medical School, Boston, Massachusetts 02115
}

Activation of either adenosine $A_{1}$ receptors or $\mathrm{GABA}_{\mathrm{B}}$ receptors inhibits many excitatory synapses in the mammalian brain. However, the extent to which different mechanisms contribute to such synaptic modulation is unclear. We examined the manner in which activation of adenosine $A_{1}$ receptors and $G A B A_{B}$ receptors modulates synaptic strength at the granule cell to Purkinje cell synapse in rat cerebellar slices. Optical determination of presynaptic calcium influx revealed that presynaptic calcium channels were modulated by 2-chloroadenosine (2CA) and baclofen, agonists of the adenosine $A_{1}$ receptor and the $\mathrm{GABA}_{B}$ receptor, respectively. $2 \mathrm{CA}$ and baclofen differentially affected three classes of calcium channels without altering the shape of the presynaptic volley, suggesting that changes in presynaptic waveform do not contribute sig- nificantly to synaptic modulation. 2CA affected neither the amplitude nor the frequency of spontaneous miniature postsynaptic currents, whereas baclofen reduced the frequency by $\sim 40 \%$ without affecting the amplitude. In addition, 2CA and baclofen do not change either fiber excitability or presynaptic residual calcium. Taken together, our data indicate that activation of the adenosine $A_{1}$ receptor reduces synaptic strength by modulating presynaptic calcium channels. Baclofen modulates presynaptic calcium channels as well but also affects release processes downstream from calcium entry.

Key words: calcium channels; presynaptic modulation; synaptic transmission; adenosine; baclofen; granule cells; Purkinje neuron
Many excitatory synapses in the mammalian brain are inhibited by activation of adenosine $A_{1}$ receptors or $G A B A_{B}$ receptors. Such inhibition may serve as a means of fine tuning synaptic strength, or as a general mechanism for synaptic depression during periods of high activity that lead to a build-up of extracellular adenosine or GABA (Silinsky et al., 1990; Isaacson et al., 1993). Considering that synaptic strength can be altered in many ways, and that presynaptic terminals are small and inaccessible, it is not surprising that it has been difficult to determine the mechanisms responsible for such modulation of transmission in the mammalian CNS.

In the study of synaptic modulation by activation of $A_{1}$ and $\mathrm{GABA}_{\mathrm{B}}$ receptors, it is useful to consider ways in which synaptic strength can be changed. (1) The threshold for fiber activation can be modulated, leading to an alteration in stimulus-evoked synaptic currents (Sabatini and Regehr, 1995). (2) A change in action potential waveform can affect the activation of voltage-gated calcium channels, thereby indirectly affecting the calcium signal available to trigger neurotransmitter release. Such a change in action potential waveform could arise in a number of ways, including activation of potassium channels (Gahwiler and Brown, 1985). (3) Modulation of presynaptic calcium channels may contribute to synaptic modulation. Although modulation of somatic calcium currents has been observed widely (Anwyl, 1991), there is relatively little direct evidence regarding the modulation of presynaptic calcium channels involved in transmitter release. (4) Modification of steady-state calcium levels in presynaptic termi-

\footnotetext{
Received Sept. 26, 1995; revised Nov. 20, 1995; accepted Dec. 1, 1995.

This work was supported by National Institutes of Health Grant R01-NS32405-01, a McKnight Scholars Award, and a Klingenstein Fellowship Award in the Neurosciences to W.R. We thank Isabelle Mintz for help and advice in setting up these studies. We thank Ken Swartz, Bernardo Sabatini, and P. S. G. Atluri for comments on this manuscript. Pfizer generously provided $\omega$-Aga-IVA for these experiments.

Correspondence should be addressed to Wade G. Regehr, Department of Neurobiology, Harvard Medical School, 220 Longwood Avenue, Boston, MA 02115. Copyright (C) 1996 Society for Neuroscience $0270-6474 / 96 / 161623-11 \$ 05.00 / 0$
}

nals can affect synaptic strength (Zucker et al., 1991). (5) Transmission can be modulated presynaptically, downstream of calcium influx. Changes in the frequency of miniature EPSCs (mEPSCs), which are caused by spontaneous fusion of single vesicles (Fatt and Katz, 1952), are thought to reflect such modulation (see Discussion). (6) Postsynaptic neurotransmitter sensitivity can be altered (Greengard et al., 1991). This list of ways to modulate synaptic strength, although not exhaustive, is a useful starting point in the examination of synaptic modulation.

Many of these mechanisms have been implicated in the modulation of synaptic transmission by activation of the adenosine $A_{1}$ receptor and the $\mathrm{GABA}_{\mathrm{B}}$ receptor. Activation of either of these G-protein-coupled receptors modulates somatic calcium channels in many types of cells (Anwyl, 1991; Mintz and Bean, 1993; Umemiya and Berger, 1994). At some synapses, inhibition of presynaptic calcium influx by adenosine or baclofen is thought to contribute to changes in synaptic strength (Yawo and Chuhma, 1993; Wu and Saggau, 1994, 1995). In addition, activation of $A_{1}$ and $\mathrm{GABA}_{\mathrm{B}}$ receptors can decrease $\mathrm{mEPSC}$ frequency, implicating presynaptic changes that are downstream from calcium influx (Prince and Stevens, 1992; Scanziani et al., 1992). Furthermore, baclofen, a selective $\mathrm{GABA}_{\mathrm{B}}$-receptor agonist, and adenosine have both been shown to modulate potassium channels and affect the action potential waveform (Alford and Grillner, 1991; Greene and Haas, 1991). It is apparent from these studies that the activation of $A_{1}$ receptors and $G \Lambda B A_{B}$ receptors can have complex actions. However, the relative contribution of these mechanisms remains much debated.

Here we study the inhibition of synaptic transmission by 2-chloroadenosine (2CA), an $\mathrm{A}_{1}$-receptor agonist, and by baclofen at the granule cell to Purkinje cell synapse in the cerebellum. This synapse is well suited to these studies because synaptic currents can be voltage-clamped (Llano et al., 1991) and changes in presynaptic calcium influx produced by single stimuli can be 
measured optically using the fluorescence transients of low-affinity calcium indicators (Mint< et al., 1995; Regehr and Atluri, 1995). We find that activation of the $A_{1}$ receptor affects transmission at this synapse almost exclusively by modulating calcium channels sensitive to $\omega$-agatoxin-IVA ( $\omega$-Aga-IVA) and $\omega$-conotoxinGVIA (CgTx). Baclofen also reduces synaptic strength by modulating these two types of calcium channels, but appears to have additional presynaptic effects downstream from calcium entry.

\section{MATERIALS AND METHODS}

Synaptic physiology, Transverse slices (250-300 $\mu \mathrm{m}$ thick) were cut from the cerebellar vermis of 9- to 14-d-old Sprague-Dawley rats. Slices were superperfused at $1-2 \mathrm{ml} / \mathrm{min}$ with an external solution containing (in $\mathrm{mm}$ ): $125 \mathrm{NaCl}, 2.5 \mathrm{KCl}, 2 \mathrm{CaCl}_{2}, 1 \mathrm{MgCl}_{2}, 26 \mathrm{NaHCO}_{3}, 1.25 \mathrm{NaH}_{2} \mathrm{PO}_{4}$, and 25 glucose, bubbled with $95 \% \mathrm{O}_{2} / 5 \% \mathrm{CO}_{2}$. Bicuculline $(20 \mu \mathrm{M})$ was added to the external solution to suppress inhibitory synaptic currents.

Whole-cell recordings of Purkinje cells were obtained as described previously (Regehr and Mintz, 1994) using 1.5-2.5 M 2 glass pipettes containing an internal solution of (in mM): $35 \mathrm{CsF}, 100 \mathrm{CsCl}, 10 \mathrm{EGTA}$, $10 \mathrm{~K}-\mathrm{HEPES}$, and $0.1 \mathrm{D} 600$, adjusted to $\mathrm{pH} 7.2-7.3$ with $\mathrm{CsOH}$. The access resistance ( $<5 \mathrm{M} \Omega$ after series resistance compensation) and leak current $(-20$ to $-200 \mathrm{pA})$ were monitored continuously. Experiments were terminated and data rejected if either parameter varied significantly during recording.

Parallel fibers were activated by injecting a current pulse through a 10-15 $\mu \mathrm{m}$ saline-filled glass electrode placed in the molecular layer several hundred micrometers from the recording site. The stimulus intensity was adjusted to keep synaptic currents sufficiently small so that uncompensated series resistance voltage errors were $<4 \mathrm{mV}$. The EPSC decay time course varied between 5 and $7.5 \mathrm{msec}$. The recording was allowed to stabilize for 15-20 min after break-in, and control EPSCs were recorded for $\sim 10$ min before any pharmacological manipulation of synaptic transmission. $\Lambda \mathrm{t}$ the end of the experiments, $100 \mu \mathrm{M}$ cadmium was added, allowing us to record the stimulus artifact in isolation. The stimulus artifact was removed for clarity in Figures $1 B$ and $2 B$.

2CA and baclofen (Research Biochemicals, Natick, MA) were prepared as stock solutions in distilled water $(10 \mathrm{mM})$ and stored at $-20^{\circ} \mathrm{C}$. Dilutions to final concentrations were made just before recording. Peptide toxins were prepared as described previously (Mintz et al., 1995). Currents were filtered at $1 \mathrm{kHz}$ and digitized every $100 \mu \mathrm{sec}$. All experiments were done at $21-24^{\circ} \mathrm{C}$. Averages are given as mean \pm SEM.

Fluorometric detection of calcium transients. Parallel fibers were labeled with a high-pressure stream of Furaptra-AM (also known as mag-Fura-2; Molecular Probes, Eugene, OR) or mag-Fura-5 as described previously (Regehr and Tank, 1991; Regehr and Atluri, 1995). Fluorescence was measured with a photodiode, and the output was filtered at $500 \mathrm{~Hz}$ with a 4-pole Bessel filter (Warner, Hamden, CT) and digitally recorded with a 16-bit converter (Instrutech, Great Neck, NY) using PULSE CONTROL software (Herrington and Bookman, 1994). The $\Delta F / F$ ratio was calculated and used as a linear measure of presynaptic calcium influx as established previously (Regehr and Atluri, 1995).

Monitoring resting calcium. Fura-2 was used to test for changes in resting calcium. Parallel fibers were labeled for $10 \mathrm{~min}$ with a highpressure stream of Fura-2 AM. After allowing $2 \mathrm{hr}$ for the dye to equilibrate, resting calcium levels were determined using the ratio method with 350 and $380 \mathrm{~nm}$ illumination. A Sutter filter wheel was used to alternate between excitation filters. Fluorescence transients produced by single stimuli were recorded in parallel to ensure that the effect on calcium influx by $2 \mathrm{CA}$ and baclofen had reached steady state.

Measuring presynaptic action potential waveform and fiber threshold. Field potentials were recorded by placing a saline-filled electrode ( $2 \mathrm{M} \Omega$ resistance) between 400 and $800 \mu \mathrm{m}$ away from the stimulus electrode in the molecular layer. Parallel fiber stimulation produced a stereotyped waveform (Eccles et al., 1967) that corresponded to the current flow during a propagating action potential. The amplitude of the presynaptic volley was defined as the peak-to-peak magnitude. Bicuculline $(20 \mu \mathrm{M})$ and 6-cyano-7-nitroquinoxaline-2,3-dione (CNQX; $2 \mu \mathrm{M}$ ) were added to the extracellular solution to minimize contamination by postsynaptic currents.

Stimulus threshold effects. Changes in fiber stimulus threshold (Fig. 3) altered the curve relating EPSC amplitude and calcium influx (Fig. 4). To assess the magnitude of this effect, we divided the EPSC and calcium influx values by the relative number of fibers stimulated. For $2 \mathrm{CA}$ the

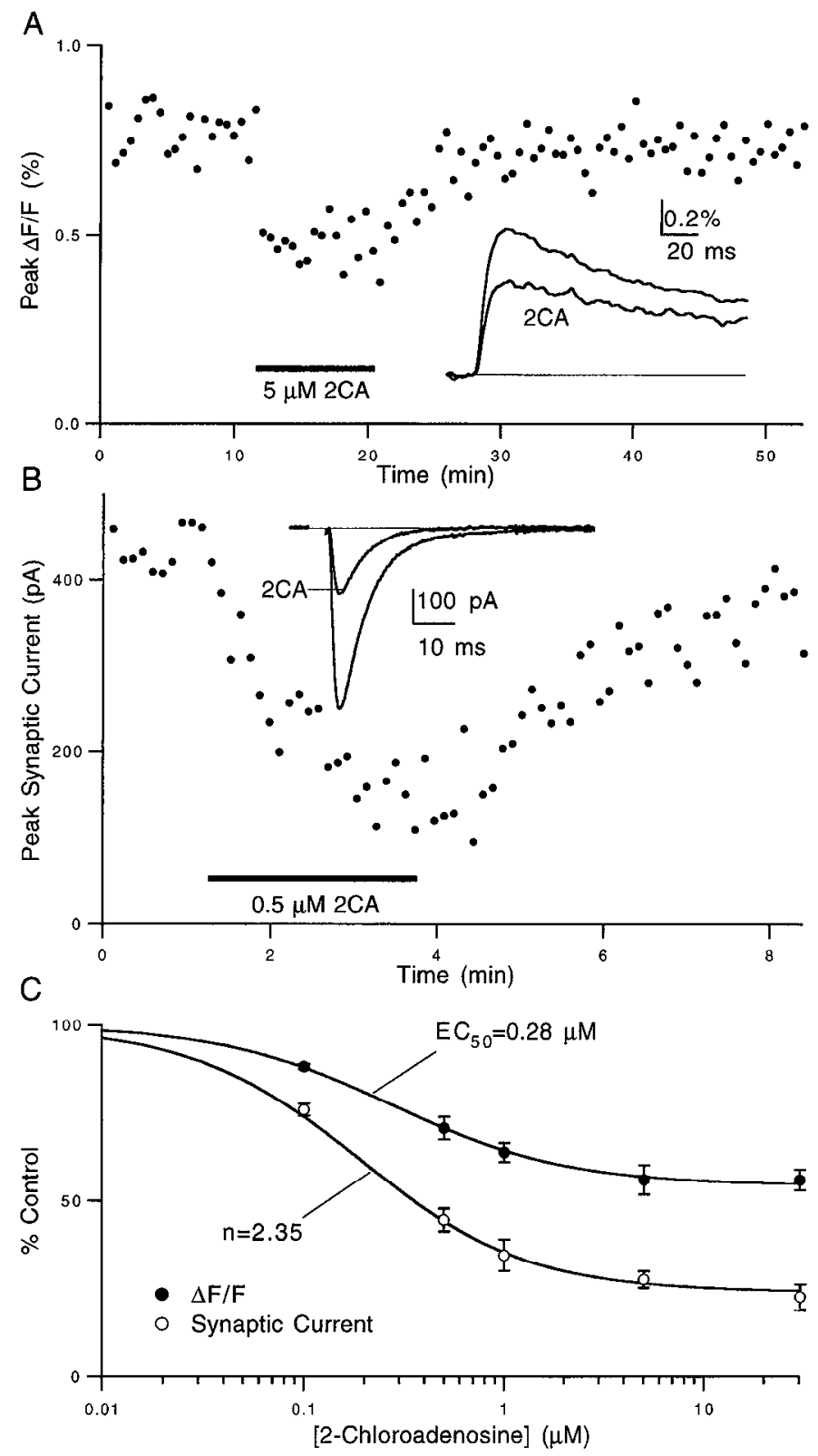

Figure 1. Reduction of calcium influx and synaptic currents by $2 \mathrm{CA}$. Reduction of peak mag-Fura-5 fluorescence transients $(A)$ and peak EPSCs $(B)$ during exposure to 2CA. Insets are averages of 10-15 traces. $C$, Dose dependence of the reduction of peak fluorescence transients (solid circles) and peak synaptic currents (open circles). Curves in $C$ are described in text. Data points are mean \pm SEM for three to six experiments.

power-law relationship between calcium influx and EPSC amplitude changed from 2.35 to 2.5 , and for baclofen it changed from 4.3 to 4.6 . Because of the small size of these effects, Figure 4 was not corrected for changes in parallel fiber threshold.

Measurement of MEPSCs. Purkinje cell spontaneous EPSCs were recorded in whole-cell configuration using 2-2.5 $\mathrm{M} \Omega$ glass pipettes in the presence of $0.2-0.5 \mu \mathrm{M}$ tetrodotoxin (TTX) to block evoked synaptic transmission and $20 \mu \mathrm{M}$ bicuculline to suppress spontaneous IPSCs. Cadmium $(100 \mu \mathrm{M})$ did not affect the amplitude or frequency of mEPSCs $(n=3)$. We tested a number of recording conditions and found that an external solution without cadmium combined with the following internal solution-facilitated stable recordings of mEPSCs (in mM): $88 \mathrm{Cs}_{2} \mathrm{SO}_{4}, 10$ EGTA, $4 \mathrm{MgSO}_{4}, 4 \mathrm{CaCl}_{2}, 1.5 \mathrm{MgCl}_{2}, 4 \mathrm{Na}_{2}$-ATP, $0.4 \mathrm{Na}_{3}$-GTP, 0.1 D600, adjusted to $\mathrm{pH} 7.3$ with $\mathrm{CsOH}$. 
Data were collected in $20 \mathrm{sec}$ epochs, filtered at $500 \mathrm{~Hz}$ with an 8-pole Bessel filter (Frequency Devices, Haverhill, MA), and digitized every 400 $\mu$ sec. The access resistance was $<10 \mathrm{M} \Omega$, and no series resistance compensation was used to minimize noise contributions from the voltageclamp circuit. The root-mean-square current for a typical experiment was $5 \mathrm{pA}$. Some data were recorded using sagittal slices, but there was no apparent difference between sagittal and transverse slices with regard to mEPSC frequency or amplitude. Events were counted and analyzed off-line using IGOR PRO software (WaveMetrics, Lake Oswego, OR). The criteria for inclusion were an 8-10 pA amplitude threshold, a rise time (10-90\%) between 1 and $5 \mathrm{msec}$, and a half-decay time between 4 and $15 \mathrm{msec}$. Overlapping events were rejected. The rejected events typically accounted for $<20 \%$ of the total number of detected events. Amplitude histograms were binned with $2 \mathrm{pA}$ intervals. To detect changes in amplitude, the amplitude histograms were integrated and normalized. As cumulative distributions, histograms were compared using the Kolmogorov-Smirnov test for significance. For the data shown here, statistical significance was assumed when $p=0.05$.

\section{RESULTS}

\section{The modulation of presynaptic calcium influx and synaptic strength by $2 \mathrm{CA}$ and baclofen}

Experiments were performed to determine whether alterations of presynaptic calcium influx contribute to inhibition of synaptic transmission by baclofen and 2CA. The relationship between synaptic strength and presynaptic calcium cntry was detcrmincd by recording synaptic currents with whole-cell voltage clamp and by detecting changes in calcium influx optically, with the calciumsensitive fluorophore Furaptra (Raju et al., 1989; Regehr and Atluri, 1995) or mag-Fura-5. By using these low-affinity indicators ( $K_{\mathrm{D}}$ for calcium of $\sim 49$ and $23 \mu \mathrm{M}$ for Furaptra and mag-Fura-5, respectively) (Delbono and Stefani, 1993), we avoided distortion of fluorescence signals, as occurred for high-affinity dyes such as Fura-2 under similar experimental conditions (Regehr and Atluri, 1995). Thus, as described previously, we were able to use $\Delta F / F$ signals produced by single stimuli to accurately measure changes in calcium entering the presynaptic tcrminals during an action potential (Mintz et al., 1995; Regehr and Atluri, 1995).

2 C.A reduced calcium influx and synaptic strength in a dosedependent manner (Fig. 1). As shown for a representative experiment, 2CA reversibly inhibited presynaptic calcium entry (Fig. $1 A)$. The peak synaptic current was also reduced by $2 \mathrm{CA}$, as shown for the experiment of Figure $1 B$. The reduction in $\Delta F / F$ (which is proportional to calcium influx) was approximated well by a function of the form $A_{\infty}+\left(100-A_{\infty}\right) /\left(1+[2 \mathrm{CA}] / \mathrm{EC}_{50}\right)$, with $\mathrm{EC}_{50}=0.28 \mu \mathrm{M}$ and $A_{\infty}=54.5 \%$ (Fig. $1 C$ ). Peak EPSC values were fit by this function raised to the $n$th power [EPSC $\propto$ $\left.\left([\mathrm{Ca}]_{\text {influx }}\right)^{n}, n=2.35\right]$.

Baclofen also reduced presynaptic calcium influx and synaptic strength, as shown for representative experiments in Figure 2, $A$ and $B . \Delta F / F$ values were fit by $A_{\infty}+\left(100-A_{\infty}\right) /(1+$ [baclofen] $/ \mathrm{EC}_{50}$ ), with $\mathrm{EC}_{50}=1.4 \mu \mathrm{M}$ and $A_{\infty}=39.5 \%$, and peak EPSCs were fit to this function raised to the $n$th power ( $n$ $=4.3$; Fig. $2 C$ ).

\section{The effect of baclofen and 2CA on resting calcium levels}

Small changes in resting calcium levels could affect synaptic transmission. We measured the effects of baclofen and 2CA on resting calcium levels using ratiometric measurements of the indicator Fura-2 and found that $30 \mu \mathrm{M}$ baclofen and $30 \mu \mathrm{M} 2 \mathrm{CA}$ did not affect resting calcium levels (data not shown).
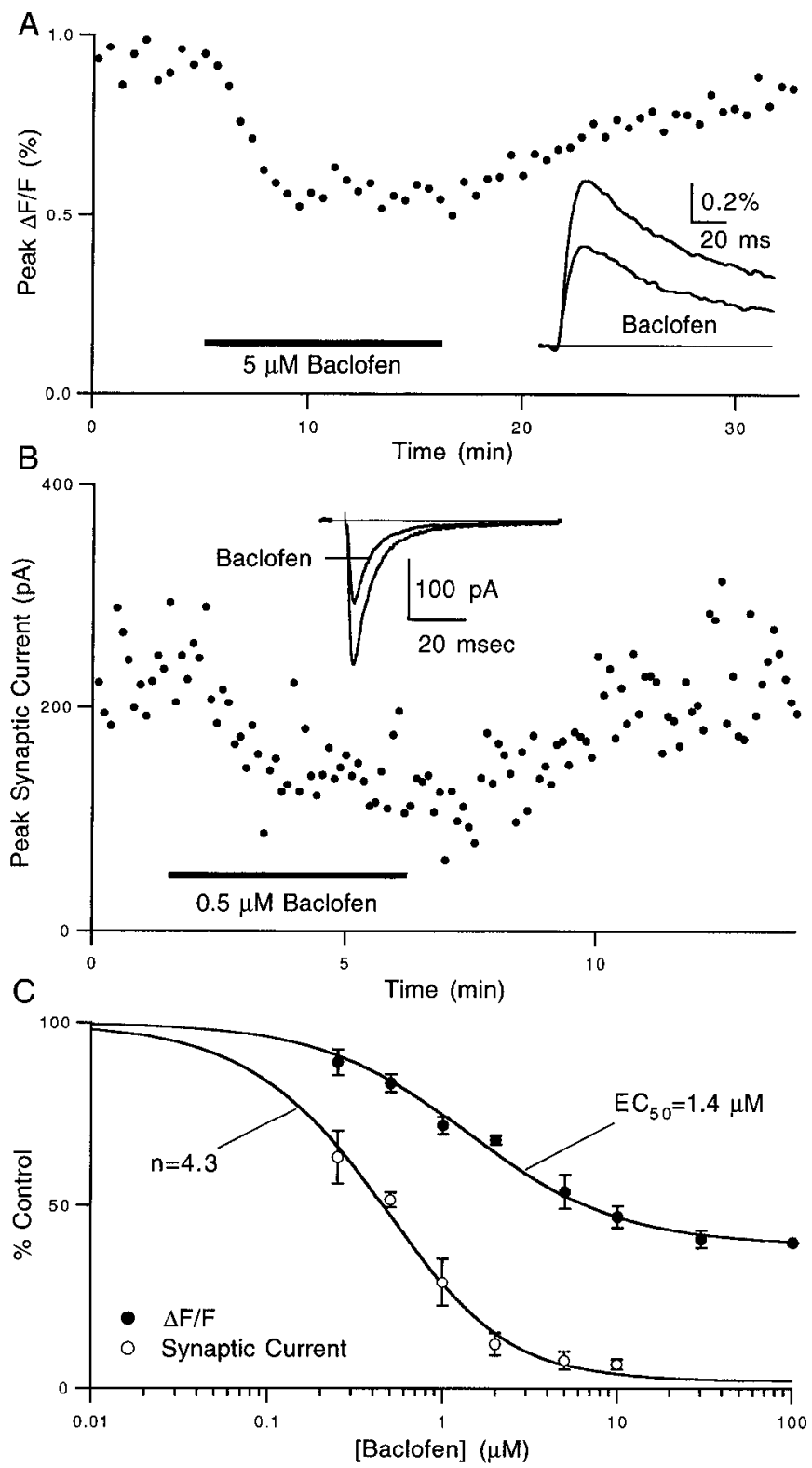

Figure 2. Reduction in calcium influx and synaptic currents by baclofen. Reduction of peak mag-Fura-5 fluorescence transients $(A)$ and peak EPSCs $(B)$ during exposure to Baclofen. Insets are averages of $10-15$ traces. $C$, Dose dependence of the reduction of peak fluorescence transients (solid circles) and peak synaptic currents (open circles). Curves in $C$ are described in text. Data points are mean \pm SEM for three to six experiments.

\section{The effect of adenosine and baclofen on the action potential waveform and the number of fibers stimulated}

We tested for possible effects of 2CA and baclofen on the number of parallel fibers activated by extracellular stimulation. The presynaptic volley, which is caused by extracellular current flow associated with action potentials propagating in parallel fibers, serves as a sensitive measure of the number of fibers activated. Figure 3, $A$ and $B$, shows the amplitude of the presynaptic volley during application of $2 \mathrm{CA}$ and baclofen. $2 \mathrm{CA}$ slightly reduced the number of fibers stimulated without a clear dose dependence (Fig. 
A

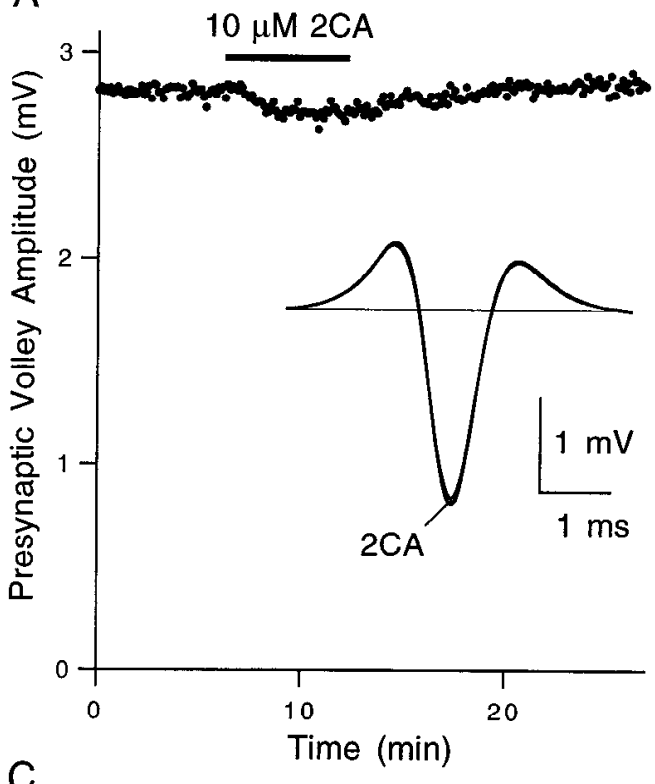

C

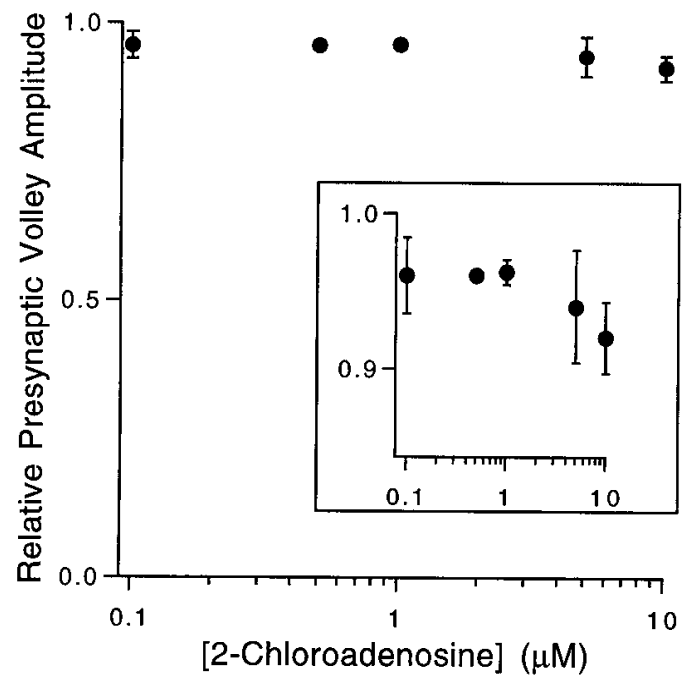

B

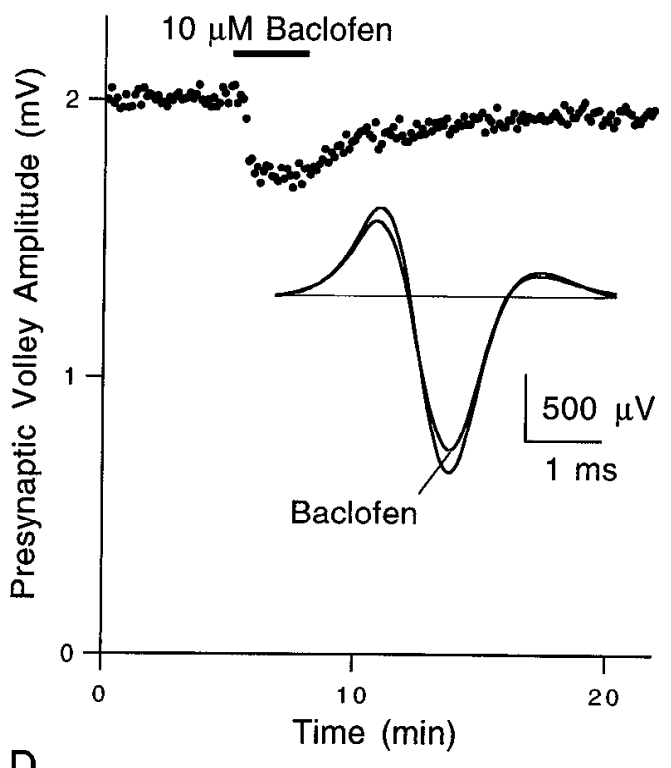

D

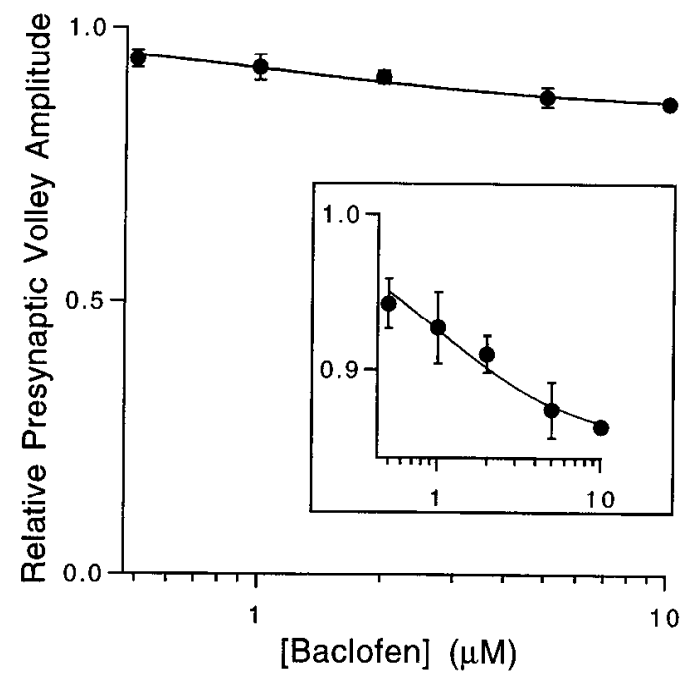

Figure 3. Effects of 2CA and baclofen on parallel fiber threshold and action potential waveform. Presynaptic volley amplitude as a function of time during exposure to $10 \mu \mathrm{M} 2 \mathrm{CA}(A)$ and $10 \mu \mathrm{M}$ Baclofen $(B)$. Insets are averages of 10-15 traces. Dose-response curves for $2 \mathrm{CA}(C)$ and Baclofen $(D)$. Insets show the same data on an expanded scale. In $D$ the solid curve is a fit to a function of the form $A_{\infty}+\left(100-A_{\infty}\right) /\left(1+[\mathrm{Baclofen}] / \mathrm{EC}_{50}\right)$, with EC $\mathrm{E}_{50}=$ $1.0 \mu \mathrm{M}$ and $A_{\infty}=85 \%$. Data points are mean $\pm \operatorname{SEM}(n=3-6)$.

$3 C$ ). Baclofen had a small but more pronounced effect on the number of fibers stimulated (Fig. 3D).

The reduction in the number of parallel fibers activated will contribute to the effect of baclofen and 2CA on calcium influx and synaptic strength. However, correcting the data in Figures 1 and 2 for changes in fiber activation does not change significantly the relationship between calcium influx and release for either $2 \mathrm{C} \Lambda$ or baclofen (see Materials and Methods).

Measurement of the presynaptic volley waveform facilitates detection of broadening or narrowing of the presynaptic action potential, which could alter the activation of voltage-gated calcium channels. As shown in Figure $3, A$ and $B$ (insets), baclofen and $2 \mathrm{CA}$ affect the amplitude but not the shape of the presynaptic volley. This suggests that the reduction of calcium influx described in Figures 1 and 2 arises directly by modulating calcium channels, rather than indirectly by altering the presynaptic waveform (but see Discussion).

\section{The relationship between calcium influx and synaptic strength for activation of the $A_{1}$ receptor and the $\mathrm{GABA}_{\mathrm{B}}$ receptor}

It appears that EPSC amplitude is more stecply dependent on calcium influx for baclofen $(n=4.3)$ than for 2CA $(n=2.35)$. Figure $4 A$ shows the relationship between EPSC amplitude and calcium influx for various concentrations of these modulators. The curves in Figure $4 A$ are power-law fits from Figures $1 C$ and $2 C$.

It is clear that both $2 \mathrm{CA}$ and baclofen inhibit synaptic strength, and that a reduction in presynaptic calcium influx contributes to this inhibition. Is this reduction in calcium influx the sole mechanism responsible for the decrease in synaptic strength? To ad- 
A
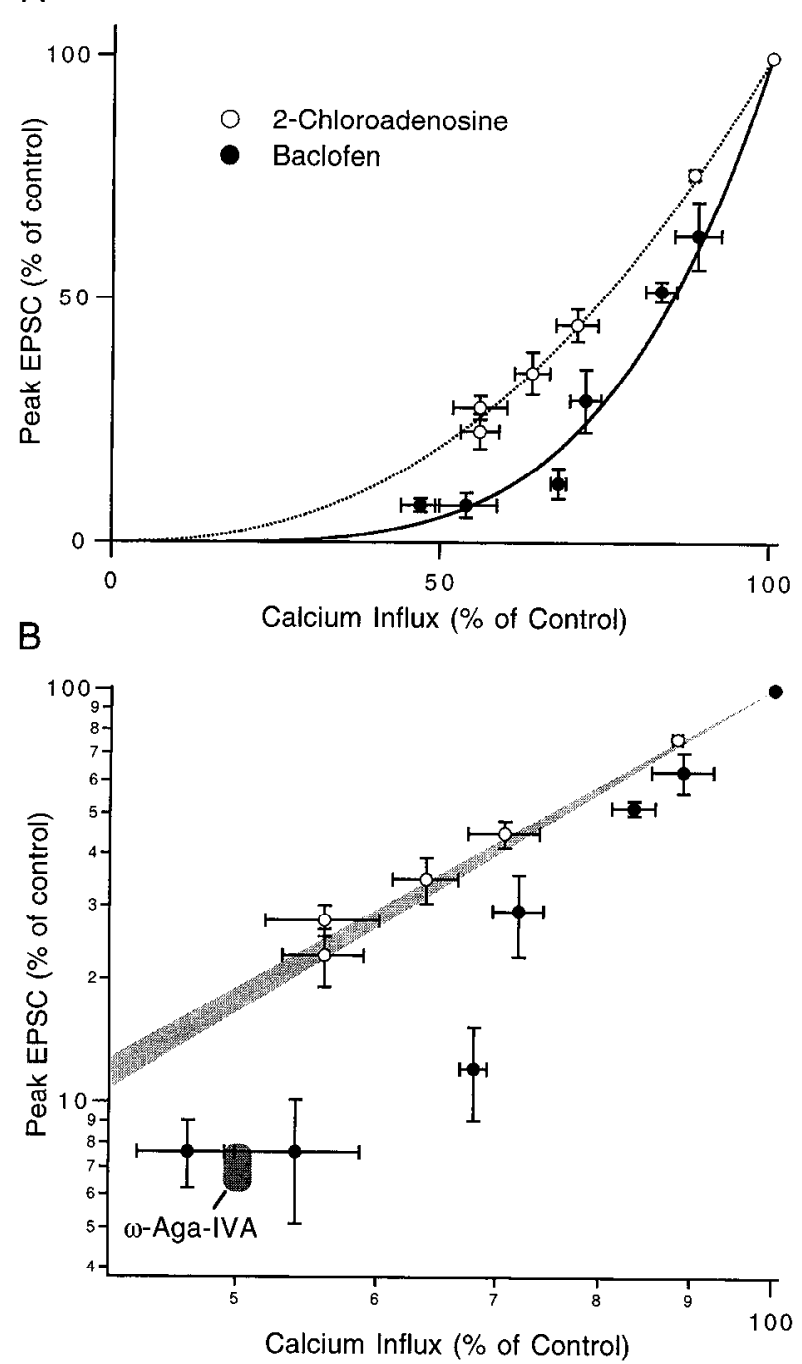

Figure 4. Relationship between presynaptic calcium influx and release. $A$, Normalized peak EPSCs are plotted as a function of normalized calcium influx for different concentrations of 2CA (open circles) and Baclofen (solid circles). Curves are power-law fits from data in Figures 1 and 2. $B$, Log-log plots of the 2CA (open circles) and Baclofen (solid circles) data compared with saturating $\omega$-Aga-IVA (shaded square). The shaded region indicates the calcium-release relationship for manipulations that specifically affect calcium influx such as low external calcium, external cadmium, or CgTx (Mintz et al., 1995). Data points are mean \pm SEM $(n=3-6)$.

dress this question, we compared the relationship between calcium influx and release for these neuromodulators with that observed when calcium entry is manipulated directly (Fig. $4 B$ ), as described in a previous study (Mint $x$ et al., 1995). In that study, we found that transmission is mediated by three pharmacologically distinct components of calcium influx: one sensitive to the calcium channel toxin ( $\omega$-Aga-IVA) (Mintz et al., 1992), another to CgTx (Williams et al., 1992; Fujita et al., 1993), and a component insensitive to both of these toxins. We also determined the relationship between calcium influx and synaptic strength when calcium influx was manipulated by changing external calcium levels, by adding the calcium channel blocker cadmium, and by adding $\omega$-Aga-IVA and/or CgTx. These studies served as a standard for relating calcium influx and synaptic strength when flux through calcium channels is altered. The light shaded region in Figure $4 B$ corresponds to the relationship between calcium and release when calcium entry is reduced by lowering external calcium, by adding external cadmium, and by adding the calcium channel antagonist CgTx. The close similarity between these conditions and the 2CA data suggests that 2CA inhibits synaptic strength primarily by reducing presynaptic calcium influx.

The power-law dependence is much steeper for baclofen than for $2 \mathrm{CA}$. Below we will examine several mechanisms that could account for this difference.

\section{Classification of presynaptic calcium channels targeted by 2CA and baclofen}

Calcium channels may be coupled differentially to release at the parallel fiber to Purkinje cell synapse (Mintz et al., 1995), so it is particularly important to determine the selectivity of 2CA and baclofen for the modulation of various types of presynaptic calcium channels. As shown in Figure $4 B$, calcium channels blocked by $\omega$-Aga-IVA (shaded rectangle) appear to be more effective at triggering release than channels blocked by $\mathrm{CgTx}$.

As shown in Figure $5 A$, after addition of maximal $2 \mathrm{CA}, \mathrm{CgTx}$ and $\omega$-Aga-IVA further reduced calcium influx. We have shown previously that CgTx and $\omega$-Aga-IVA block nonoverlapping components of calcium influx in parallel fibers and that they do not affect the amplitude or waveform of evoked presynaptic volleys (Mintz et al., 1995). Figure 5B summarizes experiments similar to that of Figurc $5 A$ and shows the fraction of calcium influx remaining in the presence 2CA. The toxin sensitivity of the fraction blocked by 2CA and the reduction of each of the components by 2CA are calculated from the fraction of calcium influx that remains in the presence of $2 \mathrm{CA}$, and the calcium influx in control conditions (27\% CgTx-sensitive, 50\% $\omega$-Aga-IVA-sensitive, and $23 \%$ toxin-insensitive) (Mintz et al., 1995). 2CA preferentially largets the CgTx-sensitive component, blocks the $\omega$-Aga-IVAsensitive fraction to a large extent, and negligibly affects the toxin-insensitive component.

Similar experiments were performed for baclofen (Fig. 6). As indicated in Figure $6 B$, baclofen also inhibited both $\omega$-Aga-IVAsensitive and $\mathrm{CgTX}$-sensitive components with little or no effect on the toxin-insensitive fraction. However, baclofen was slightly less effective at reducing entry through the CgIX-sensitive channel (74 vs $82 \%$ reduction for $\omega$-Aga-IVA), whereas $2 \mathrm{CA}$ was much more effective at reducing entry though $\mathrm{CgTx}$-scnsitive channcls than through $\omega$-Aga-IVA-sensitive channels ( 84 and $42 \%$ reduction, respectively). Such differential modulation of calcium channel components, combined with the more effective coupling of $\omega$-AgaIVA-sensitive calcium channels to release, could contribute to the differences in the relationship between calcium influx and release for baclofen and 2CA (see Discussion). These results demonstrate both specificily and overlap in the inhibition of presynaptic calcium channels, similar in many ways to descriptions of modulation of somatic calcium channels (Anwyl, 1991; Mintz and Bean, 1993; Umemiya and Berger, 1994).

\section{Effects of 2CA and baclofen on spontaneous release of neurotransmitter and postsynaptic responsiveness}

To test for presynaptic changes in synaptic transmission that are calcium-independent and to test for changes in postsynaptic glutamate responsiveness, we recorded mEPSCs in the presence of TTX and bicuculline.

We began by pharmacologically characterizing the mEPSCs. Figure $7 A$ shows a representative sample of the mEPSCs recorded at a holding potential of $-70 \mathrm{mV}$. The non-NMDA glutamatereceptor antagonist CNQX $(2 \mu \mathrm{M})$, which completely blocks 


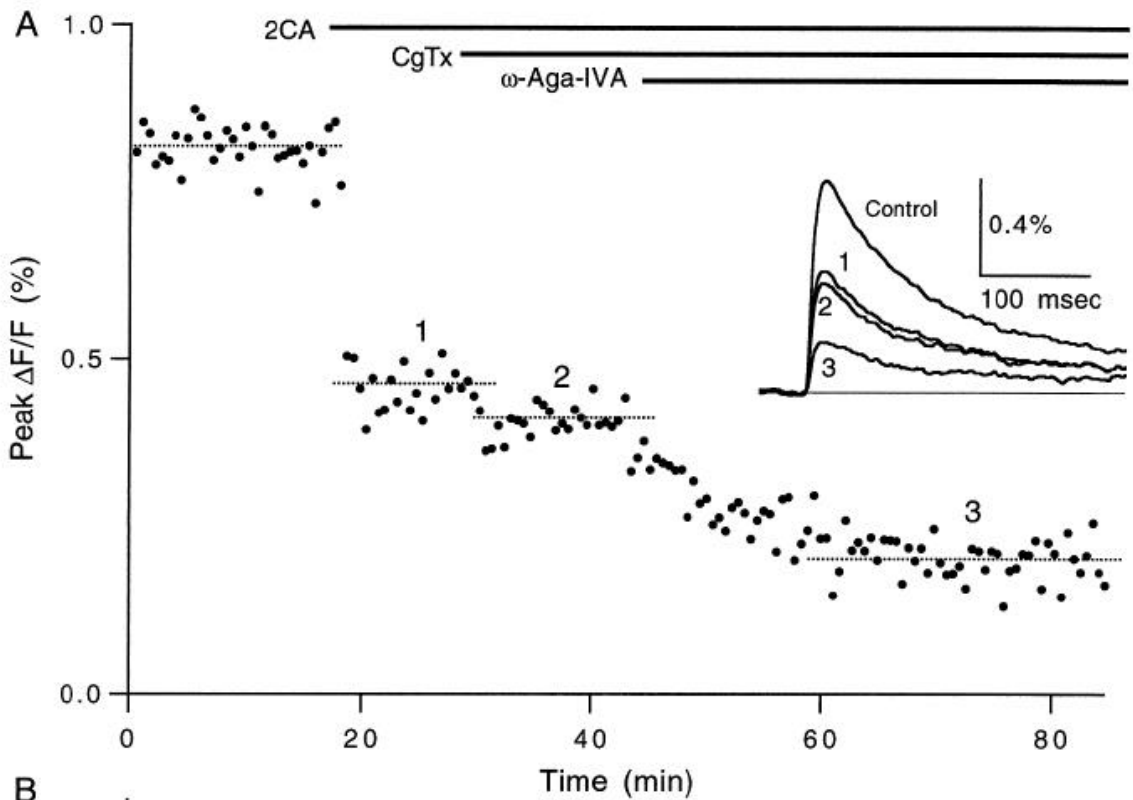

Figure 5. Selectivity of 2CA for different calcium channel types in parallel fiber presynaptic terminals. $A$, Peak $\Delta F / F$ is plotted as a function of time. $2 \mathrm{CA}$ $(30 \mu \mathrm{M}), \operatorname{CgTx}(500 \mathrm{nM})$, and $\omega$-Aga-IVA (200 nM) were added in succession. Dotted lines show average peak $\Delta F / F$ values used for analysis in $B$. Insets are averages of $10-20$ transients for steady-state condition as indicated by number. $B$, Percent reduction in peak $\Delta F / F$ for $\omega$-Aga-IVA-sensitive (dark gray), CgTx-sensitive (light gray), and toxin-insensitive (white) components. Error bars represent the SEM.

B

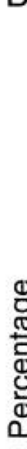

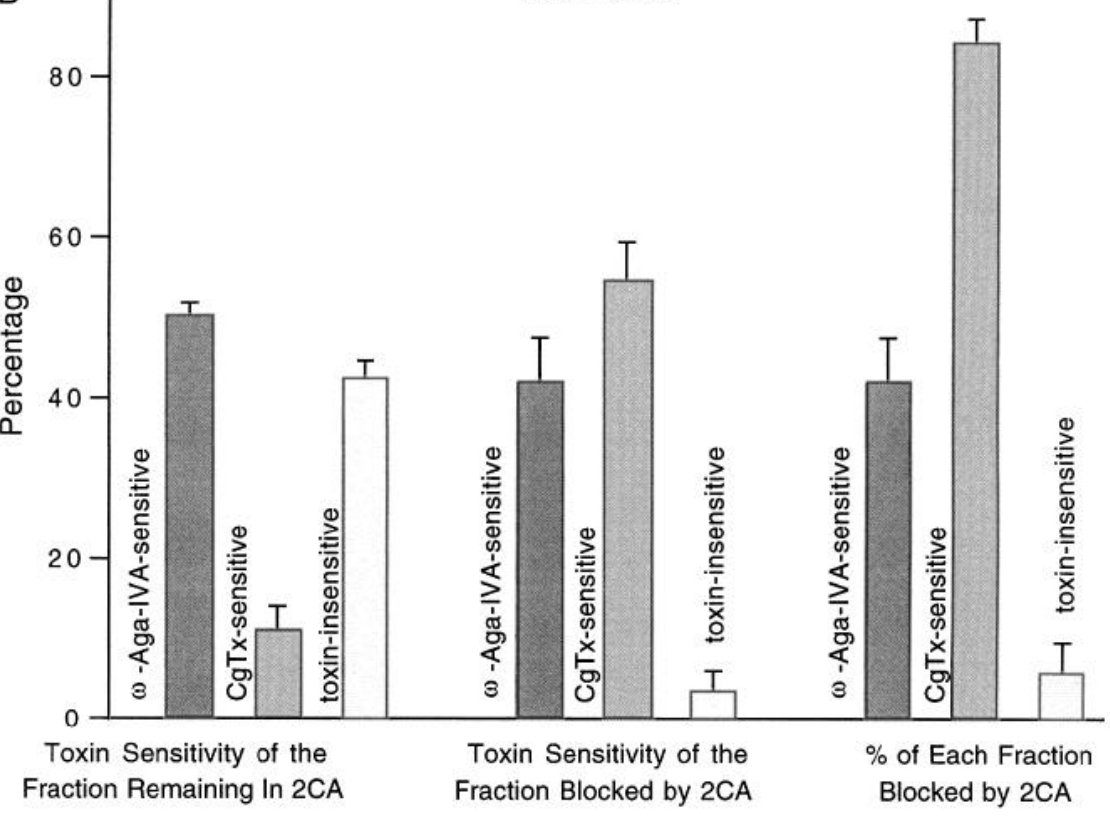

evoked parallel fiber EPSCs (Konnerth et al., 1990; Perkel et al., 1990), reversibly eliminated the mEPSCs (Fig. 7A). The time course of the mEPSCs was similar to that of evoked parallel fiber EPSCs (Fig. 7B, inset), as described previously (Barbour, 1993). The amplitude histogram in Figure $7 B$ shows the distribution of the mEPSC amplitudes recorded over $\sim 300 \mathrm{sec}$.

As shown in Figure 7, $C$ and $D$, we were able to detect changes in mEPSC amplitude. Changing the holding potential from -70 to $-50 \mathrm{mV}$ affected the amplitude distribution of the mEPSCs. The apparent frequency of mEPSCs also decreased because of loss of small events in the background noise. A normalized cumulative amplitude histogram was generated to determine whether the amplitude distribution was affected (Fig. 7D, inset). By comparing data taken at -50 and $-70 \mathrm{mV}$, a statistically significant ( $p=0.001$ by the Kolmogorv-Smirnov test) reduction in mEPSC amplitude was detected. This comparison can be used to detect amplitude changes even when there is an apparent decrease in mEPSC frequency.
As shown in Figure 8, 2CA did not affect the frequency or amplitude of mEPSCs. No significant decrease was observed in 5 $\mu \mathrm{M} 2 \mathrm{CA}(5.5 \pm 3.4 \% ; n=3)$. The amplitude distributions for mEPSCs in the presence and absence of $2 \mathrm{CA}$ were virtually identical (Fig. $8 C$ ). There was no significant effect $(p=1.00)$ on mEPSC amplitude, as shown in Figure $8 C$ (inset). Changing the holding potential from -70 to $-50 \mathrm{mV}$ in the same experiment caused a detectable change in the normalized cumulative amplitude histogram ( $p=0.03$; data not shown).

In contrast, baclofen substantially reduced the mEPSC frequency $(39.8 \pm 2.9 \% ; n=4)$ as shown in Figure 9. The amplitude distribution for this experiment is shown in Figure $9 C$. The normalized cumulative amplitude distribution showed no significant change $(p=0.86)$ in the presence of $5 \mu \mathrm{M}$ baclofen. Changing the holding potential from -70 to $-50 \mathrm{mV}$ caused a significant change in the cumulative amplitude distribution during the same experiment ( $p=0.05$; data not shown). This suggests that a majority of the mEPSC frequency decrease in the presence of 
A
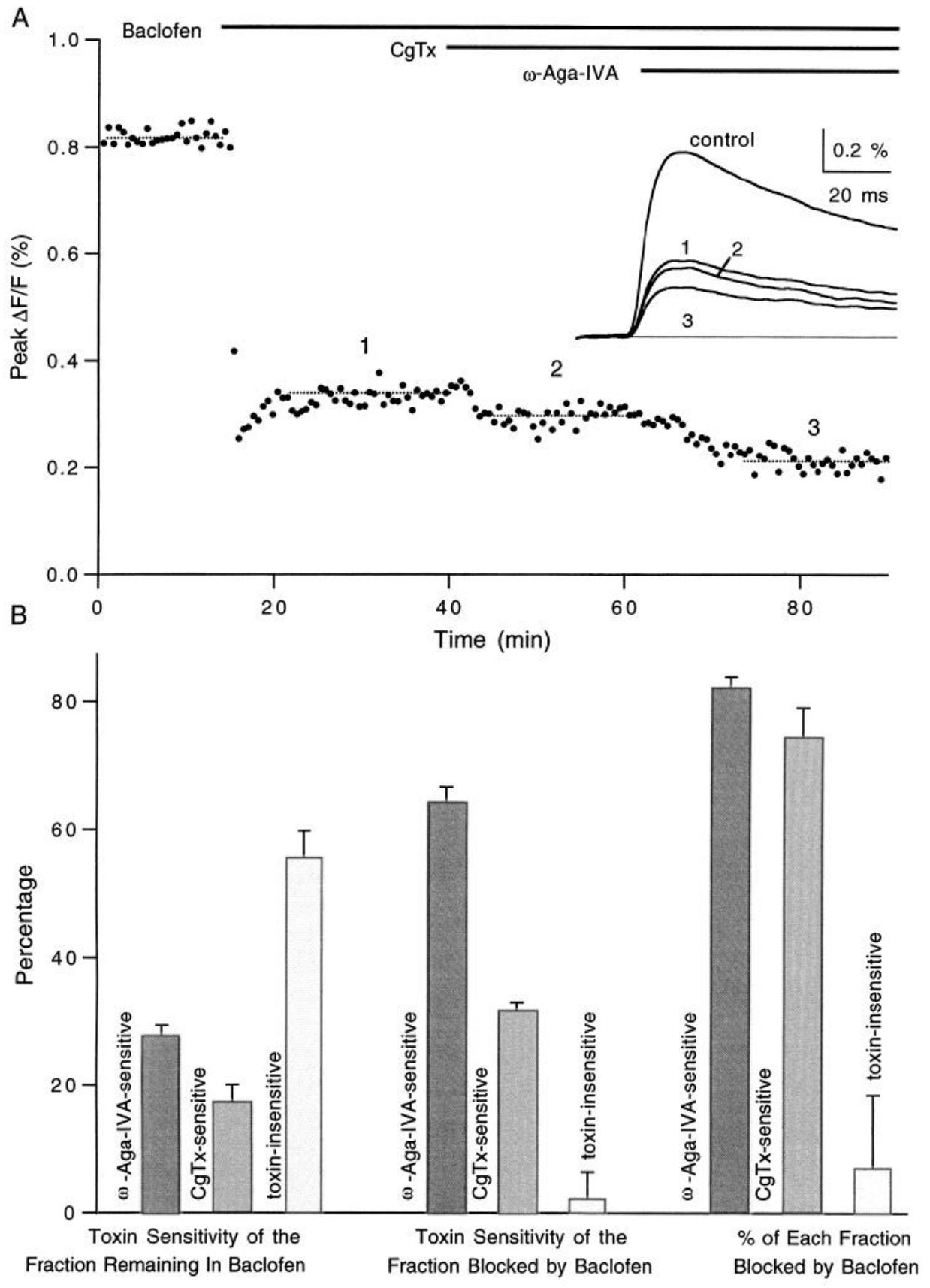

Figure 6. Selectivity of baclofen for different calcium channel types in parallel fiber presynaptic terminals. $A$, Peak $\Delta F / F$ is plotted as a function of time. Baclofen $(30 \mu \mathrm{M})$, CgTx (500 nM), and $\omega$-Aga-IVA (200 nM) were added in succession. Dotted lines show average peak $\triangle F / F$ values used for analysis in $B$. Insets are averages of $10-20$ transients for each condition as indicated by number. $B$, Fractional reduction in peak $\Delta F / F$ for $\omega$-Aga-IVA-sensitive (dark gray), $\mathrm{CgTx}$ sensitive (light gray), and toxin-insensitive (white) components. Error bars represent the SEM. baclofen cannot be accounted for by a decrease in mEPSC amplitude. Thus, baclofen decreases mEPSC frequency without substantially affecting postsynaptic glutamate sensitivity.

\section{DISCUSSION}

We used several approaches to study synaptic inhibition at the parallel fiber to Purkinje cell synapse by activation of $\mathrm{GABA}_{B}$ receptors and adenosine $A_{1}$ receptors. Our findings lend support to the view that modulation of presynaptic calcium channels is an important means of controlling synaptic strength. We also find that synaptic modifications can arise from multiple mechanisms acting in concert. The relative contributions of a number of mechanisms to synaptic inhibition are discussed in detail below.

\section{Parallel fiber excitability}

In our experiments, parallel fibers were activated with an extracellular electrode, as has been the case in most studies of synaptic transmission in the CNS. A change in fiber excitability would contribute to changes in stimulus-evoked synaptic currents by affecting the number of fibers activated (Sabatini and Regehr, 1995). Because baclofen and 2CA are known to modulate a variety of channel types, including potassium channels (Gahwiler and Brown, 1985; Proctor and Dunwiddie, 1987; Greene and Haas, 1991; Thompson and Gahwiler, 1992), these neuromodulators may affect fiber excitability.

We found that 2CA had only minor effects on the number of fibers excited, in accord with previous studies in the hippocampus (Dunwiddie, 1984). Baclofen reduced the number of excited fibers to a slightly larger extent. The reduction of the 
A

Figure 7. Purkinje cell mEPSCs. A: Top trace, Typical Purkinje cell mEPSCs recorded in $0.2 \mu \mathrm{M}$ TTX and $20 \mu \mathrm{M}$ bicuculline at a holding potential of $-70 \mathrm{mV}$. Middle trace, $1 \mathrm{~min}$ after exposure to $2 \mu \mathrm{M}$ CNQX. Bottom trace, 10 min after washout (Wash) of CNQX. B, Amplitude histogram for $\sim 1450$ events recorded in 300 sec binned in $2 \mathrm{pA}$ intervals with a threshold of $8 \mathrm{pA}$. Inset, Single mEPSC fit to a sum of two exponentials with rising and decaying $\tau$ values of 2.5 and $3.6 \mathrm{msec}$, respectively. $C$, mEPSCs recorded at -70 $\mathrm{mV}$ (top), $-50 \mathrm{mV}$ (middle), and returned to $-70 \mathrm{mV}$ (bottom). $D$, Amplitude histograms for holding potential of $-70 \mathrm{mV}$ (thin line) and $-50 \mathrm{mV}$ (thick line). Inset shows the normalized cumulative amplitude distributions for $-70 \mathrm{mV}$ (thin) and $-50 \mathrm{mV}$ (thick) holding potentials. The difference in amplitude is significant with $p=0.001$ according to the Kulnugorov-Smirnov statistic. Data are from $300 \mathrm{sec}$ of recording with 929 events for $-70 \mathrm{mV}$ and 507 events for $-50 \mathrm{mV}$.

B

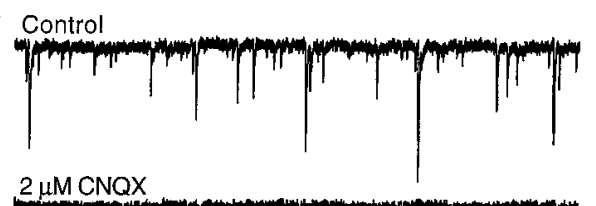

$2 \mu \mathrm{M}$
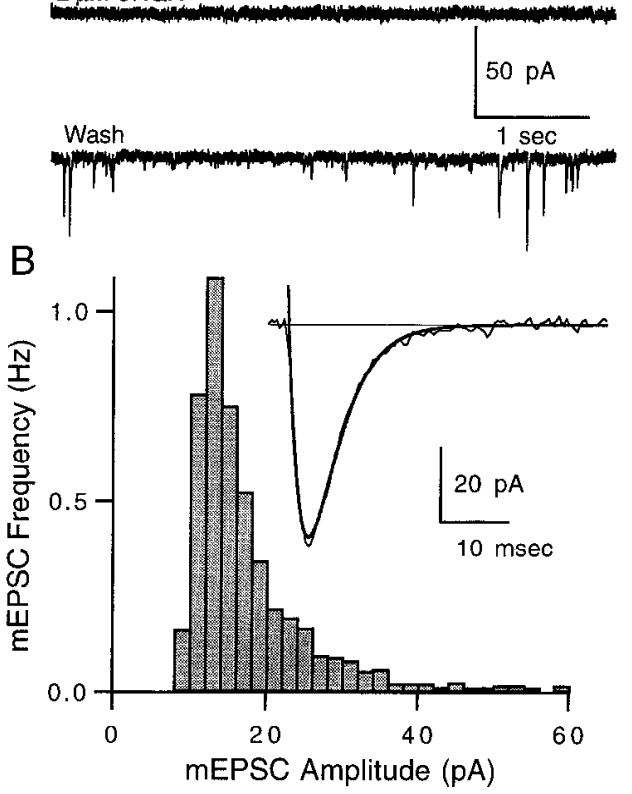

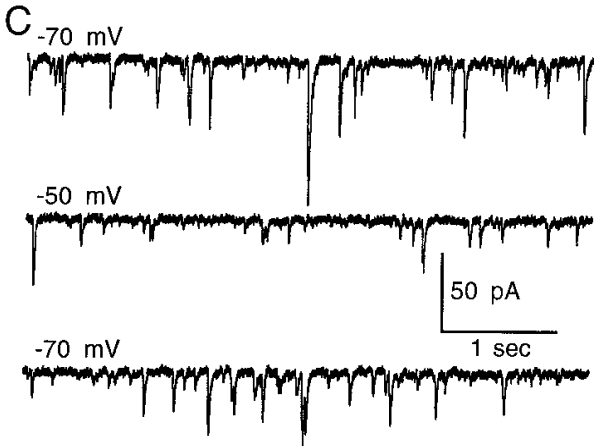

$\mathrm{D}$

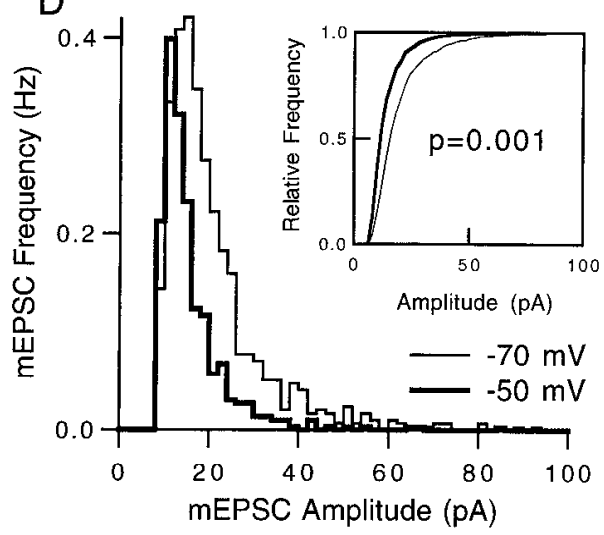

number of fibers stimulated was sufficiently small that it did not greatly affect the relationship between calcium influx and EPSC amplitude.

\section{Alteration of presynaptic waveform}

Calcium channel activation can be extremely sensitive to spike width (Augustine, 1990), and spike broadening contributes to modulation of some synapses (Klein and Kandel, 1980; Alford and Grillner, 1991). We therefore considered the possibility that changes in presynaptic action potential waveform contribute to synaptic modulation by $2 \mathrm{CA}$ and baclofen. These modulators did not affect the shape of the presynaptic volley, which is sensitive to small waveform changes produced by low concentrations of tetraethylammonium (B. Sabatini and W. Regehr, unpublished observations). It is difficult, however, to exclude subtle waveform changes in the presynaptic terminals that could not be detected with an extracellular electrode. We also found that the various components of calcium influx were affected to very different degrees. This suggests that the presynaptic waveform is unchanged, because such an alteration would affect influx through all types of calcium channels similarly (unless they differed dramatically in their activation properties) (McCobb and Beam, 1991). Taken together, the two lines of evidence described here suggest that changes in presynaptic waveform do not contribute significantly to synaptic modulation by $2 \mathrm{CA}$ and baclofen. More sensitive measures of the waveform in presynaptic terminals, and determination of the activation kinetics of the calcium channel components, will clarify further the participation of presynaptic waveform changes in synaptic modulation at this synapse.

\section{Presynaptic residual calcium levels}

Residual calcium levels have been shown to influence release at many synapses (Delaney et al., 1989; Swandula et al., 1991; Delaney and Tank, 1994; Kamiya and Zucker, 1994; Regehr et al.,
1994). It appears that even modest increases in calcium can enhance the probability of release by acting at a high-affinity calcium-binding site distinct from the site involved in triggering vesicle fusion. We tested the possibility that activation of the $A_{1}$ receptor and the $\mathrm{GABA}_{\mathrm{B}}$ receptor might influence synaptic strength by altering steady-state calcium levels in presynaptic boutons. This was not the case, because ratiometric imaging of Fura-2 levels showed that $2 \mathrm{CA}$ and baclofen had no effect on resting calcium levels.

\section{Postsynaptic effects}

Postsynaptic changes did not contribute to synaptic inhibition by baclofen and 2CA. Synaptic currents were voltage-clamped under conditions in which potassium channels and calcium channels in the Purkinje cell did not affect the synaptic currents (see Materials and Methods). 'This still leaves open the possibility that a decrease in postsynaptic sensitivity to glutamate (Greengard et al., 1991) could contribute to synaptic inhibition. By comparing amplitude distribution histograms for mEPSCs in Purkinje cells, we found no significant changes in glutamate sensitivity in the presence of baclofen or 2CA. This observation is consistent with similar experiments performed in the hippocampus (Prince and Stevens, 1992; Scanziani et al., 1992).

\section{Modulation of presynaptic calcium channels}

There has been a great deal of debate about the relative contribution of calcium channel modulation to synaptic modulation in the CNS. By quantitating changes in presynaptic calcium influx with calcium indicators, we have shown that presynaptic calcium influx is reduced by $2 \mathrm{CA}$ and baclofen. These findings are in agreement with previous results that implicate calcium channel modulation in altering synaptic strength at other synapses (Scholz and Miller, 1991; Yawo and Chuhma, 1993; Umemiya and Berger, 1994; Wu and Saggau, 1994, 1995).

By detecting changes in calcium influx with low-affinity cal- 
A
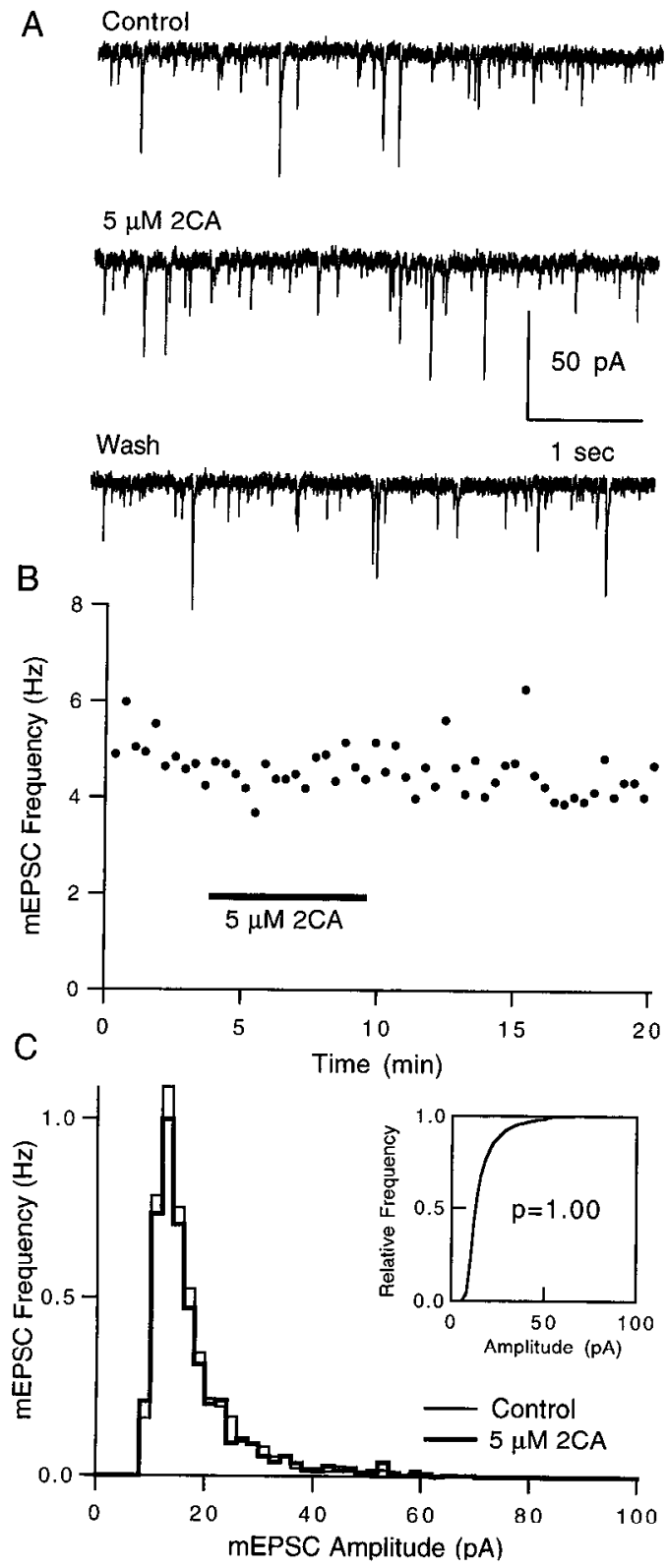

Figure 8. Effects of 2CA on Purkinje cell mEPSCs. $A$, mEPSCs recorded at a holding potential of $-70 \mathrm{mV}$ before (top), during (middle), and after (bottom) application of $5 \mu \mathrm{M} 2 \mathrm{CA}$. $B$, The average mEPSC frequency in $20 \mathrm{sec}$ epochs is plotted as a function of time during exposure to 2CA (bar). C, Amplitude histograms for control (thin line) and $5 \mu \mathrm{M} 2 \mathrm{CA}$ (thick line). Inset, Normalized cumulative amplitude distributions for control (thin) and 2CA (thick) do not differ significantly ( $p=1.00$ by Kolmogorov-Smirnov test). Changing the holding potential to $-50 \mathrm{mV}$ caused a significant decrease in mEPSC amplitude $(p=0.03)$ for this experiment (data not shown). Data are from $240 \mathrm{sec}$ of recording with 1161 events for the control distribution and 1120 events for the $2 \mathrm{CA}$ distribution.

cium indicators, we were able to overcome difficulties that prevented accurate quantification of changes in calcium influx in previous studies. This enabled us to evaluate the extent to which the observed reduction in presynaptic calcium influx could account for the changes in synaptic strength. As shown in Figure 4, the relationship between calcium influx and release
A

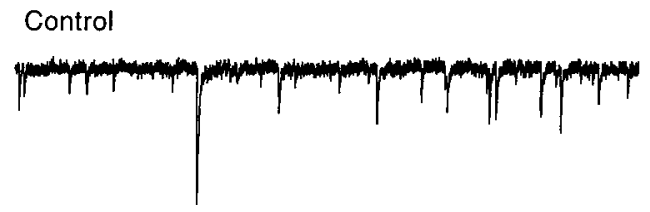

$5 \mu \mathrm{M}$ Baclofen
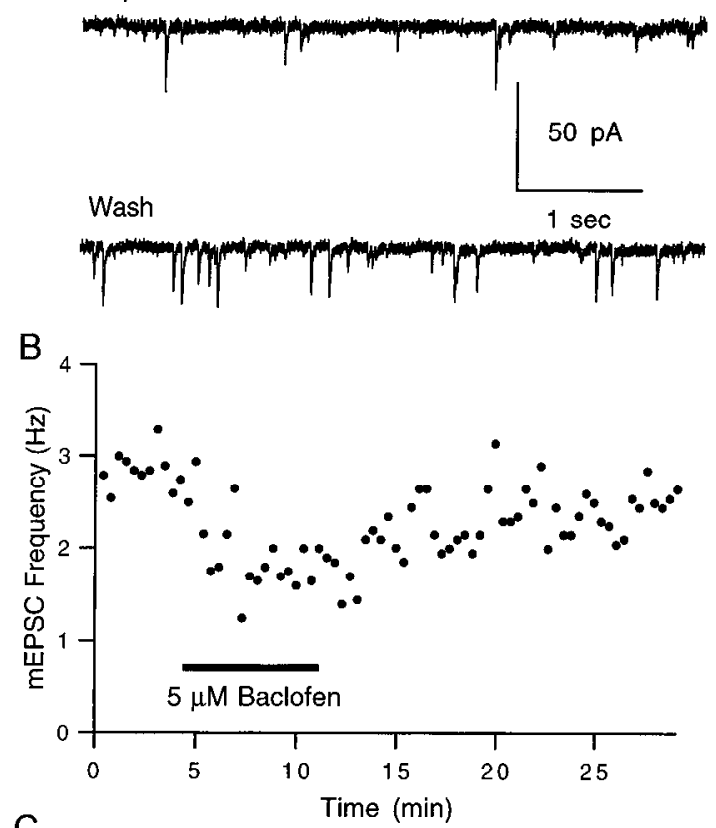

$\mathrm{C}$

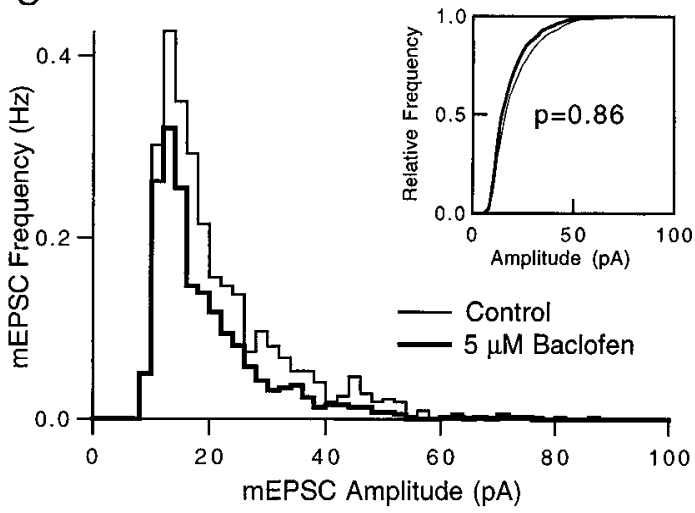

Figure 9. Effects of Baclofen on Purkinje cell mEPSCs. $A$, mEPSCs recorded at a holding potential of $-70 \mathrm{mV}$ before (top), during (middle), and after (bottom) application of $5 \mu \mathrm{M}$ Baclofen. $B$, Average mEPSC frequency for $20 \mathrm{sec}$ epochs is plotted as a function of time during exposure to Baclofen (bar). C, Amplitude histograms for control (thin line) and $5 \mu \mathrm{M}$ Baclofen (thick line). Inset, Normalized cumulative amplitude distributions for control (thin) and Baclofen (thick) do not differ significantly $(p=0.86$ by Kolmogorov-Smirnov test). Changing the holding potential to $-50 \mathrm{mV}$ caused a significant decrease in $\mathrm{mEPSC}$ amplitude $(p=0.05)$ for this experiment (data not shown). Data are from $300 \mathrm{sec}$ of recording with 828 events for the control distribution and 520 events for the Baclofen distribution.

obtained in the presence of $2 \mathrm{CA}$ was remarkably similar to that obtained when external calcium was lowered, or when the calcium channel blockers cadmium or CgTx were added. This suggested that the observed changes in calcium influx were sufficient to account entirely for the inhibition of synaptic transmission by $2 \mathrm{CA}$. 
Reduction of presynaptic calcium entry accounts for a large part of the inhibition of synaptic transmission by baclofen (Fig. 4). However, the relationship between calcium entry and release was much steeper for baclofen than for $2 \mathrm{CA}$. The more pronounced effect of baclofen on the $\omega$-Aga-IVA-sensitive channel, which may be more effectively coupled to release, appears to contribute to differences between baclofen and 2CA in their calcium-release relationship (as discussed below, this is not the only mechanism).

\section{Mechanisms downstream from calcium influx}

Because baclofen and 2CA profoundly decreased mEPSC frequency in the hippocampus (Scanziani et al., 1992), it has been proposed that inhibition of evoked synaptic currents are largely independent of changes in presynaptic calcium influx. Others have suggested that adenosine decreases either the probability of release or the number of release sites at hippocampal synapses (Prince and Stevens, 1992; Chavez-Noriega and Stevens, 1994). We found that 2CA had no measurable effects on spontaneous release at concentrations that potently reduced synaptic strength. This supports our conclusion that at the granule cell to Purkinje cell synapse, activation of the $A_{1}$ receptor decreases synaptic strength by modulating presynaptic calcium channels and not via other presynaptic mechanisms.

In contrast, baclofen decreased the average mEPSC frequency by $\sim 40 \%$, suggesting that activation of $G A B A_{B}$ receptors inhibits a process involved in transmitter release after calcium influx. We estimate that baclofen reduces synaptic strength primarily through calcium channel modulation $(70-90 \%)$, with presynaptic mechanisms downstream from calcium influx accounting for the remaining 10-30\%. These estimates are based on the calcium influx and synaptic strength curves of Figure 4.

\section{Application of this approach to other synapses}

The approach described here promises to be applicable to the study of many forms of synaptic modulation in the mammalian brain, and has great potential for resolving disputes over the relative contribution of different mechanisms to synaptic modulation. One important aspect of our approach is the ability to accurately quantify changes in calcium influx by using lowaffinity calcium indicators. Also, by studying the same preparation with multiple techniques, we can estimate the contribution of many mechanisms to synaptic modulation.

\section{REFERENCES}

Alford S, Grillner S (1991) The involvement of $\mathrm{GABA}_{\mathrm{B}}$ receptors and coupled G-proteins in spinal GABAergic presynaptic inhibition. J Neurosci 11:3718-3726.

Anwyl R (1991) Modulation of vertebrate neuronal calcium channels by transmitters. Brain Res Rev 16:265 281.

Augustine G (1990) Regulation of transmitter release at the squid giant synapse by presynaptic delayed rectifier potassium current. J Physiol (Lond) 431:343-364.

Barbour B (1993) Synaptic currents evoked in Purkinje cells by stimulating individual granule cells. Neuron 11:759-769.

Chavez-Noriega LE, Stevens CF (1994) Increased transmitter release at excitatory synapses produced by direct activation of adenylate cyclase in rat hippocampal slices. IJ Neurosci 14:310-317.

Delaney KR, Tank DW (1994) A quantitative measurement of the dependence of short-term synaptic enhancement on presynaptic residual calcium. J Neurosci 14:5885-5902.

Delaney KR, Zucker RS, Tank DW (1989) Calcium in motor nerve terminals associated with posttetanic potentiation. J Neurosci 9:3558-3567.
Delbono O, Stefani E (1993) Calcium transients in single mammalian skeletal muscle fibers. J Physiol (Lond) 463:689-707.

Dunwiddie TV (1984) Interactions between the effects of adenosine and calcium on synaptic responses in rat hippocampus in vitro. $\mathrm{J}$ Physiol (Lond) 350:545-559.

Eccles JC, Ito M, Szentagothai J (1967) The cerebellum as a neuronal machine. New York: Springer.

Fatt P, Katz B (1952) Spontaneous subthreshold activity at motor nerve endings. J Physiol (Lond) 117:109-128.

Fujita Y, Mynlieff M, Dirksen RT, Kim M-S, Niidome T, Nakai J, Friedrich T, Iwabe N, Miyata T, Furuichi T, Furutama D, Mikoshiba K, Mori Y, Beam KG (1993) Primary structure and functional expression of the $\omega$-conotoxin sensitive $\mathrm{N}$-type calcium channel from rabbit brain. Neuron 10:585-598.

Gahwiler BH, Brown DA (1985) GABA $_{\mathrm{B}}$-receptor activated $\mathrm{K}^{+}$current in voltage-clamped CA3 pyramidal cclls in hippocampal cultures. Proc Natl Acad Sci USA 82:1558-1562.

Greene RW, Haas HL (1991) The electrophysiology of adenosine in the mammalian central nervous system. Prog Neurobiol 36:329-341.

Greengard P, Jen J, Nairn AC, Stevens CF (1991) Enhancement of the glutamate response by cAMP-dependent protein kinase in hippocampal neurons. Science 253:1135-1138.

Grynkiewicz G, Poenie M, Tsien RY (1985) A new generation of $\mathrm{Ca}^{2+}$ indicators with greatly improved fluorescence properties. J Biol Chem 260:3440-3450.

Herrington J, Bookman RJ (1994) Pulse control V3.0: IGOR XOPs for patch clamp data acquisition. Miami: University of Miami.

Isaacson JS, Solis JM, Nicoll RA (1993) Local and diffuse synaptic actions of GABA in the hippocampus. Neuron 10:165-175.

Kamiya H, Zucker RS (1994) Residual $\mathrm{Ca}^{2+}$ and short-term synaptic plasticity. Nature 371:603-606.

Klein M, Kandel ER (1980) Mechanisn of calcium curtent modulation underlying presynaptic facilitation and behavioral sensitization in Aplysia. Proc Natl Acad Sci USA 77:6912-6916.

Konnerth A, Llano I, Armstrong CM (1990) Synaptic currents in cerebellar Purkinje cells. Proc Natl Acad Sci USA 87:2662-2665.

Llano I, Marty A, Armstrong CM, Konnerth A (1991) Synaptic and agonist-induced excitatory currents of Purkinje cells in rat cerebellar slices. J Physiol (Lond) 434:183-213.

McCobb DP, Beann KG (1991) Action potential waveform voltage clamp commands reveal striking differences in calcium entry via low and high voltage-activated calcium channels. Neuron 7:119-127.

Mintz IM, Bean BP (1993) GABA $_{B}$ receptor inhibition of P-type $\mathrm{Ca}^{2+}$ channels in central neurons. Neuron 10:889-898.

Mintz IM, Venema VJ, Swinderek KM, Lee TD, Bean BP, Adams ME (1992) P-type calcium channels blocked by the spider toxin $\omega$-Aga-IVA. Nature 355:827-829.

Mintz IM, Sabatini BL, Regehr WG (1995) Calcium control of transmitter release at a central synapse. Neuron 15:675-688.

Perkel DJ, Hestrin S, Sah P, Nicoll RA (1990) Excitatory synaptic currents in Purkinje cells. Proc R Soc Lond [Biol] 241:116-121.

Prince DA, Stevens CF (1992) Adenosine decreases neurotransmitter release at central synapses. Proc Natl Acad Sci USA 89:8586-8590.

Proctor WR, Dunwiddie TV (1987) Pre- and postsynaptic actions of adenosine in the in vitro rat hippocampus. Brain Res 426:187-190.

Raju B, Murphy E, Levy LA, Hall RD, London RE (1989) A fluorescent indicator for measuring cytosolic free magnesium. Am J Physiol 256:C540-C547.

Regehr WG, Atluri P (1995) Calcium transients in cerebellar granule cell presynaptic terminals. Biophys J 68:2156-2170.

Regehr WG, Tank DW (1991) Selective fura-2 loading of presynaptic terminals and nerve cell processes by local perfusion in mammalian brain slice. J Neurosci Methods 37:111-119.

Regehr WG, Delaney KR, Tank DW (1994) The role of presynaptic calcium in short-term enhancement at the hippocampal mossy fiber synapse. J Neurosci 14:523-537.

Sabatini BL, Regehr WG (1995) Detecting changes in calcium influx which contribute to synaptic modulation in mammalian brain slice. Neuropharmacology 34:1453-1467.

Scanziani M, Copogna M, Gahwiler BH, Thompson SM (1992) Presynaptic inhibition of miniature excitatory synaptic currents by baclofen and adenosine in the hippocampus. Neuron 9:919-927. 
Scholz KP, Miller RJ (1991) $\mathrm{GABA}_{B}$ receptor-mediated inhibition of $\mathrm{Ca}^{2+}$ currents and synaptic transmission in cultured rat hippocampal neurones. J Physiol (Lond) 444:669-686.

Silinsky EM, Hunt JM, Solsona CS, Hirsh JK (1990) Prejunctional adenosine and ATP receptors. Ann NY Acad Sci 603:324-333.

Swandula D, Hans M, Zipser K, Augustine GJ (1991) Role of residual calcium in synaptic depression and posttetanic potentiation: fast and slow calcium signaling in nerve terminals. Neuron 7:915-926.

Thompson SM, Gahwiler BH (1992) Comparison of the actions of baclofen at pre- and postsynaptic receptors in the rat hippocampus in vitro. J Physiol (Lond) 192:329-345.

Umemiya M, Berger AJ (1994) Activation of adenosine $A_{1}$ and $A_{2}$ receptors differentially modulates calcium channels and glycinergic synaptic transmission in rat brainstem. Neuron 13:1439-1446.
Williams ME, Brust PF, Feldman DH, Patthi S, Simerson S, Maroufi A McCrue AF, Velicelebi G, Ellis SB, Harpold MM (1992) Structure and functional expression of an $\omega$-conotoxin-sensitive human $\mathrm{N}$-type calcium channel. Science 257:389-395.

Wu L-G, Saggau P (1994) Adenosine inhibits evoked synaptic transmission primarily by reducing presynaptic calcium influx in area CA1 of hippocampus. Neuron 12:1139-1148.

Wu L-G, Saggau P (1995) GABA B $_{B}$ receptor-mediated presynaptic inhibition in guinea-pig hippocampus is caused by reduction of presynaptic $\mathrm{Ca}^{2+}$ influx. J Physiol (Lond) 485:649-657.

Yawo H, Chuhma N (1993) Preferential inhibition of $\omega$-conotoxinsensitive presynaptic $\mathrm{Ca}^{2+}$ channels by adenosine autoreceptors. Nature 365:256-258.

Zucker RS, Delaney KR, Mulkey R, Tank DW (1991) Presynaptic calcium in transmitter release and posttetanic potentiation. Ann NY Acad Sci 635:191-207. 